n.tronos

glyndîn

Glyndŵr University

Glyndŵr University Research Online

Computing

Computer Science

$10-1-2008$

\title{
Dual-Frequency Planar Inverted F-L-Antenna (PIFLA) for WLAN and Short Range Communication Systems
}

CH.See

RA. Abd-Alhameed

D Zhou

Peter S. Excell

Glyndwr University, p.excell@glyndwr.ac.uk

Follow this and additional works at: http://epubs.glyndwr.ac.uk/cair

Part of the Computer Engineering Commons, and the Computer Sciences Commons

\section{Recommended Citation}

See, C. H., Abd-Alhameed, R. A., Zhou, D. \& Excell, P. S. (2008) 'Dual-Frequency Planar Inverted F-L-Antenna (PIFLA) for WLAN and Short Range Communication Systems'. IEEE Transactions on Antennas and Propagation, 56(10), 3318-3320.

This Article is brought to you for free and open access by the Computer Science at Glyndŵr University Research Online. It has been accepted for inclusion in Computing by an authorized administrator of Glyndŵr University Research Online. For more information, please contact

d.jepson@glyndwr.ac.uk. 


\title{
Dual-Frequency Planar Inverted F-L-Antenna (PIFLA) for WLAN and Short Range Communication Systems
}

\begin{abstract}
The design and analysis is presented of a low profile and dualfrequency inverted L-F antenna for WLAN and short range wireless communications, providing a compromise between size reduction and attainable bandwidth. The optimum (minimized) volume of $30308 \mathrm{~mm}$ of the proposed antenna gives $8 \%$ bandwidth at lower resonant mode of $2400 \mathrm{MHz}$, while at the higher resonant mode of $5500 \mathrm{MHz}$ a bandwidth of $12.2 \%$ is obtained. Both the simulated and measured characteristics of the proposed antenna are shown.
\end{abstract}

\section{Keywords}

Dual-frequency antenna, inverted L-F antenna, short range wireless communication, WLAN.

\author{
Disciplines \\ Computer Engineering | Computer Sciences
}

\section{Comments}

Copyright (C) 2008 IEEE. Reprinted from the proceedings of the IEEE Transactions on Antennas and Propagation in Oct 2008. This material is posted here with permission of the IEEE and the author. Such permission of the IEEE does not in any way imply IEEE endorsement of any of the products or services of Glyndwr University Wrexham. Internal or personal use of this material is permitted. However, permission to reprint/republish this material for advertising or promotional purposes or for creating new collective works for resale or redistribution must be obtained from the IEEE by writing to pubs-permissions@ieee.org. By choosing to view this document, you agree to all provisions of the copyright laws protecting it. The definitive version is available at http://ieeexplore.ieee.org 
[3] Microstrip Antennas: The Analysis and Design of Microstrip Antennas and Arrays, D. M. Pozar and D. H. Schaubert, Eds. New York: Wiley/ IEEE Press, 1995.

[4] P. Bhartia, Millimeter-Wave Microstrip and Printed Circuit Antennas. Boston, MA: Artech House, 1991.

[5] Advances in Microstrip and Printed Antennas, K. F. Lee, Ed. New York: Wiley, 1997.

[6] R. Garg, P. Bhartia, I. J. Bahl, and A. E. Ittipiboon, Microstrip Antenna Design Handbook. Boston, MA: Artech House, 2001.

[7] R. B. Waterhouse, Microstrip Patch Antennas: A Designer's Guide. New York: Kluwer Academic, 2003.

[8] R. Bancroft, Microstrip and Printed Antenna Design. New York: Noble Publishers, 2004.

[9] C. A. Balanis, Antenna Theory: Analysis and Design, 3rd ed. New York: Wiley, 2005, pp. 727-752.

[10] D. M. Pozar, "Input impedance and mutual coupling of rectangular microstrip antennas," IEEE Trans. Antennas Propag., vol. 30, no. 6, pp. 1191-1196, Nov. 1982

[11] L. I. Basilio, M. A. Khayat, J. T. Williams, and S. A. Long, "The dependence of the input impedance on feed position of probe and microstrip line-fed patch antennas," IEEE Trans. Antennas Propag., vol. 49, pp. 45-47, Jan. 2001.

[12] R. Zhong, X. Tang, L. Wang, and X. Zhang, "Study of microstrip-line inset-fed and two-layer electromagnetically coupled rectangular patch antennas," in Proc. Asia Pacific Microwave Conf. (APMC), Dec. 2005, vol. 4, pp. 4-7.

[13] T. Samaras, A. Kouloglou, and J. N. Sahalos, "A note on the impedance variation with feed position of a rectangular microstrip-patch antenna," IEEE Trans. Antennas Propag., vol. 46, pp. 90-92, Apr. 2004.

[14] G. Ghione and C. Naldi, "Parameters of coplanar waveguides with lower ground plane," Electron. Lett., vol. 19, no. 18, Sep. 1983.

[15] S.-C. Wu, N. G. Alexopoulos, and O. Fordham, "Feeding structure contribution to radiation by patch antennas with rectangular boundaries," IEEE Trans. Antennas Propag., vol. 40, pp. 1245-1249, Oct. 1992.

\section{Dual-Frequency Planar Inverted F-L-Antenna (PIFLA) for WLAN and Short Range Communication Systems}

\author{
C. H. See, R. A. Abd-Alhameed, D. Zhou, and P. S. Excell
}

\begin{abstract}
The design and analysis is presented of a low profile and dualfrequency inverted L-F antenna for WLAN and short range wireless communications, providing a compromise between size reduction and attainable bandwidth. The optimum (minimized) volume of $30 \times 30 \times 8 \mathrm{~mm}$ of the proposed antenna gives $8 \%$ bandwidth at lower resonant mode of $2400 \mathrm{MHz}$, while at the higher resonant mode of $5500 \mathrm{MHz}$ a bandwidth of $12.2 \%$ is obtained. Both the simulated and measured characteristics of the proposed antenna are shown.
\end{abstract}

Index Terms-Dual-frequency antenna, inverted L-F antenna, short range wireless communication, WLAN.

\section{INTRODUCTION}

With the rapid growth of wireless LAN applications, there is a concomitant demand for low cost and small sized antenna designs for commercial markets. Due to its low profile and ability to cover the ex-

Manuscript received January 2, 2008; revised April 11, 2008. Current version published October 3, 2008.

C. H. See, R. A. Abd-Alhameed, and D. Zhou are with the Mobile and Satellite Communications Research Centre, Bradford University, Bradford, BD7 1DP, U.K. (e-mail: r.a.a.abd@bradford.ac.uk).

P. S. Excell is with North East Wales Institute of Higher Education, Wrexham LL11 2AW, U.K.

Digital Object Identifier 10.1109/TAP.2008.929537

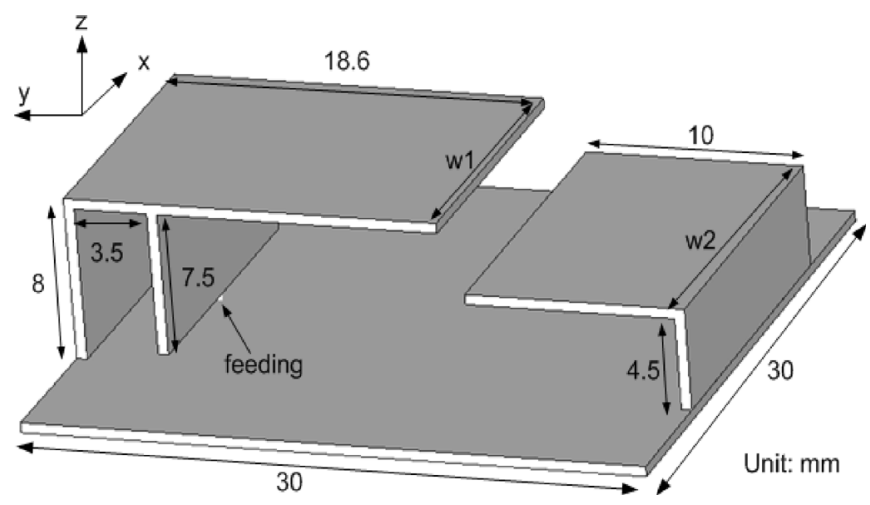

Fig. 1. Geometry of the proposed F-L antenna.

isting wireless communication frequency bands, the planar inverted F-antenna (PIFA) has been widely adopted in portable wireless units [1]-[6]. Due to the limited space available on the printed circuit board (PCB) of a wireless device, antenna miniaturization is crucial to keep the size of this type of antenna small and appropriate for portable wireless units, without degradation of performance in terms of bandwidth and radiation patterns. Studies of ground plane effects [7] and bandwidth enhancement methods [8], [9] of such antennas have been reported.

By adapting the research outcomes of authors [7]-[10], this paper presents a new dual-frequency $(2.5 / 5.5 \mathrm{GHz})$ compact planar inverted F-L-shaped antenna with overall size of $30 \mathrm{~mm} \times 15 \mathrm{~mm} \times 8 \mathrm{~mm}$, mounted on a $30 \mathrm{~mm} \times 30 \mathrm{~mm}$ finite ground plane. The target frequencies were chosen to cover IEEE802.11x and systems such as Bluetooth and ZigBee.

\section{ANTENNA DESIGN}

Fig. 1 depicts the geometry of the proposed antenna, the maximum dimension being about a quarter-wavelength at the centre frequency for IEEE $802.11 \mathrm{~b} / \mathrm{g}$ and Bluetooth $(2450 \mathrm{MHz})$ : the maximum height of the antenna from the finite ground plane is about $7 \%$ of the free space operating wavelength and the thickness of the copper conductors is $0.5 \mathrm{~mm}$. A modified planar inverted $\mathrm{F}$ radiating element is adopted, having a rectangular plate feed element because of its attractive enhanced bandwidth characteristics [8].

The object of the proposed design is to implement multiple radiating elements, i.e., inverted $\mathrm{F}$ and $\mathrm{L}$, each of them supporting strong currents and radiation at the two resonances. The inverted $\mathrm{F}$ antenna is designed to operate at fundamental resonant frequency, while the inverted L antenna is introduced to operate at the desired upper operating frequency. Due to the strong coupling between the two radiating elements, simple design formulas cannot be found, and so two EM simulators (CST [11] and IE3D [12]) were used to perform the analysis and achieve the optimum performance of the proposed antenna. It should be noted that the ground plane size of the antenna was chosen to fit in the limited space available in most wireless transceiver circuit board and casings for portable devices.

As can be seen from Fig. 1, there are two variable parameters, w1 and $w 2$. To assess the influence of these parameters on the impedance bandwidth, a parametric study was carried out by varying each parameter sequentially, while holding the remaining parameter values at their initial values (arbitrarily chosen to be well within the desired envelope): these values for $\mathrm{w} 1$ and $\mathrm{w} 2$ were $10 \mathrm{~mm}$ and $17 \mathrm{~mm}$ respectively. The results (using CST) are shown in Fig. 2(a) and (b), from which the optimum values of $\mathrm{w} 1$ and $\mathrm{w} 2$ were found to be $15 \mathrm{~mm}$ and $11 \mathrm{~mm}$ 


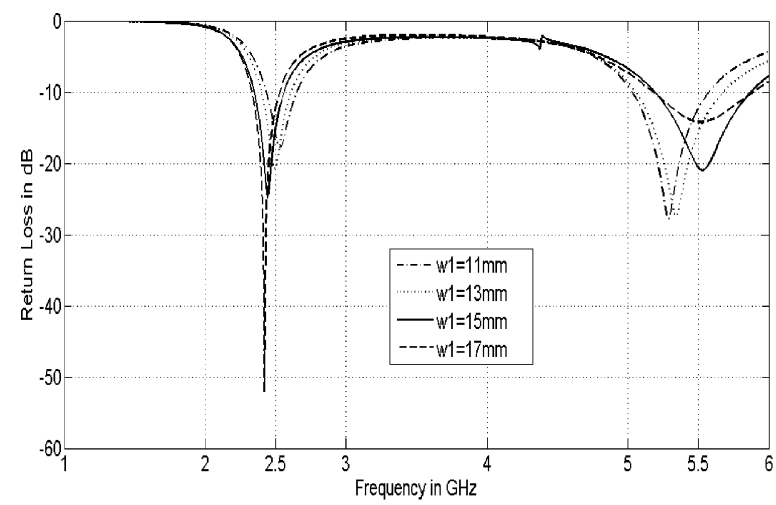

(a)

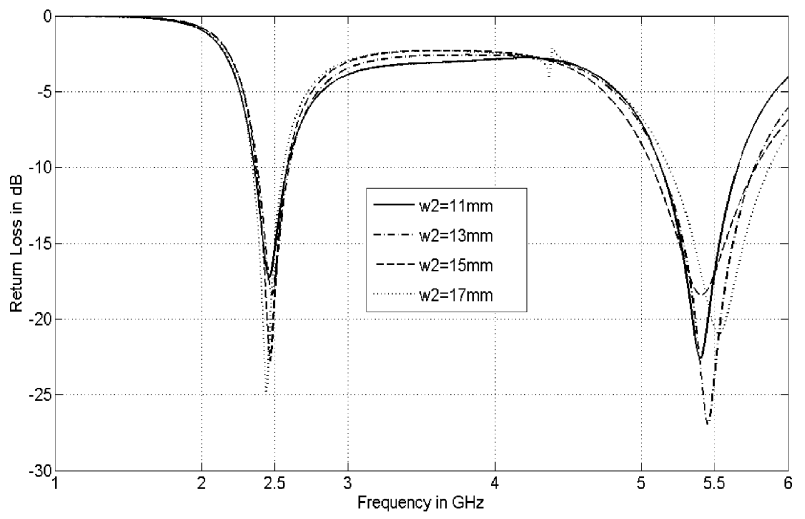

(b)

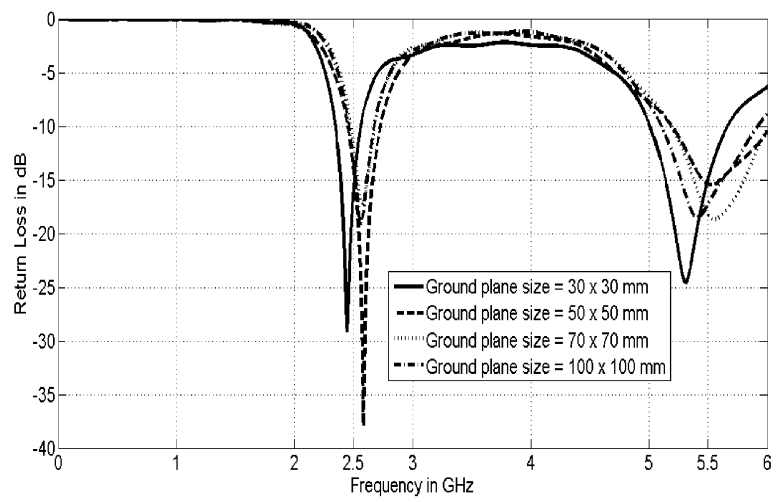

(c)

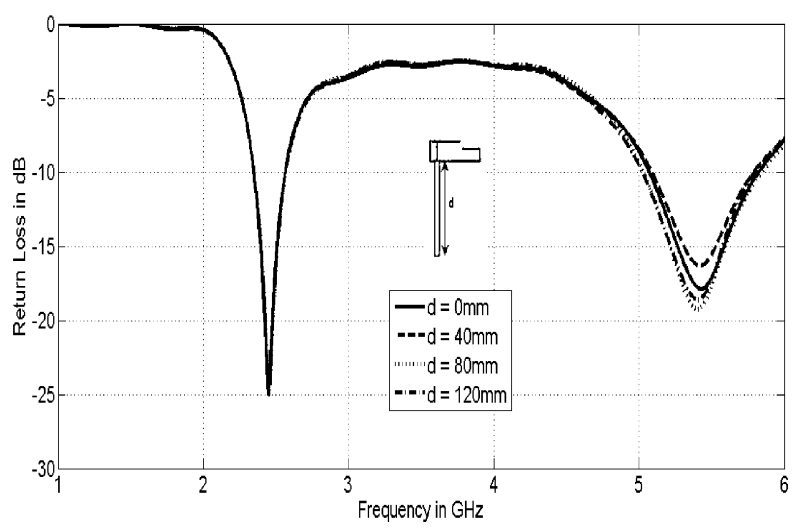

(d)

Fig. 2. Simulated return losses with variation of parameters: (a) $\mathbf{w} \mathbf{1}$; (b) w2 $\mathbf{2}$; (c) ground plane size; (d) coaxial length $\mathbf{d}$.

respectively, for the best performance of the proposed antenna at resonant frequencies of $2450 \mathrm{MHz}$ and $5200 \mathrm{MHz}$. Moreover, in order

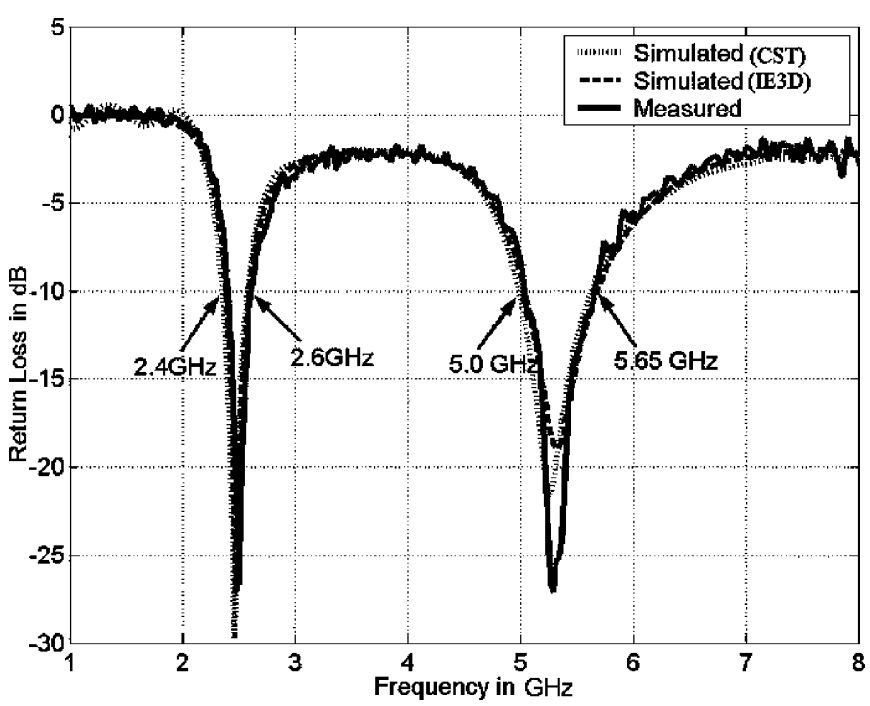

Fig. 3. Measured and simulated return losses.

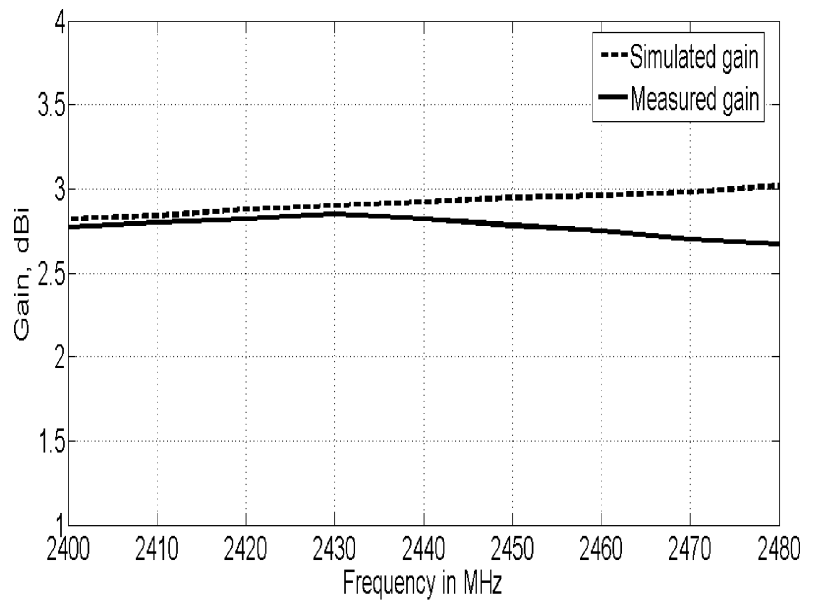

(a)

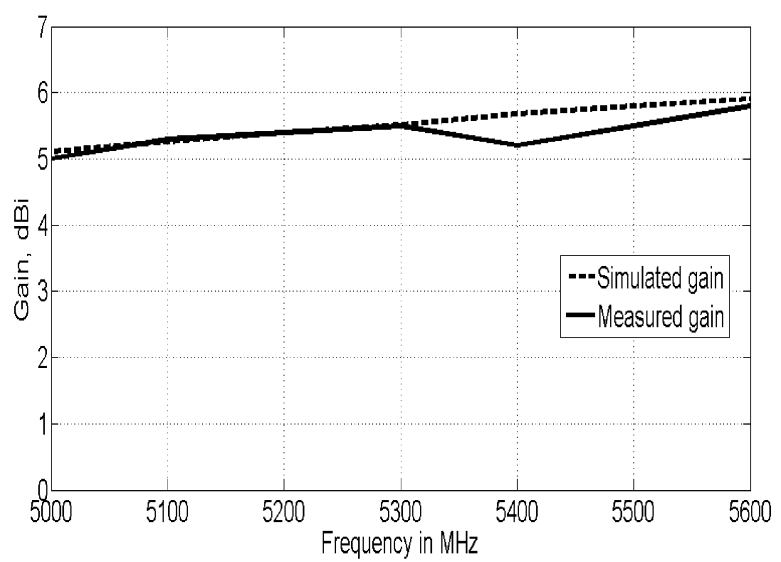

(b)

Fig. 4. Measured gains for proposed antenna: (a) upper band; (b) lower band.

to understand the effect of the ground plane of the proposed antenna, simulations were conducted to check the variations of the return loss against the size of the ground plane. From Fig. 2(c), it is seen that increased ground plane sizes, from $50 \mathrm{~mm}$ to $100 \mathrm{~mm}$, do not contribute any significant bandwidth enhancement. Conversely, the larger ground planes make the antenna inconvenient for personal devices and move 

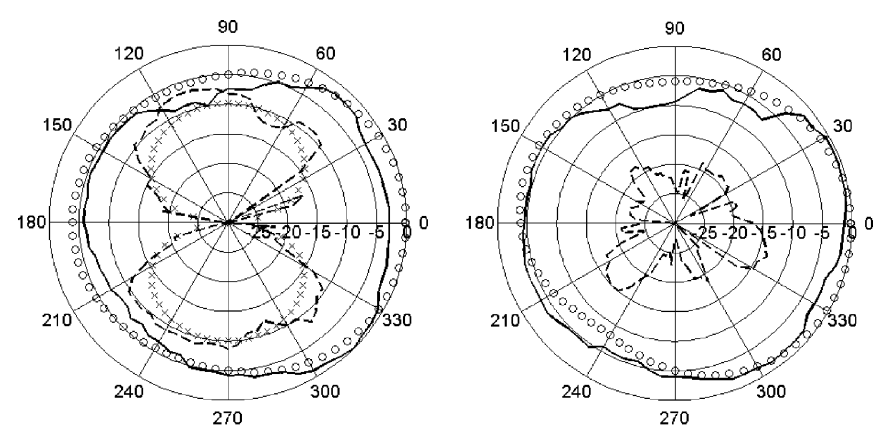

(a) $2450 \mathrm{MHz}$
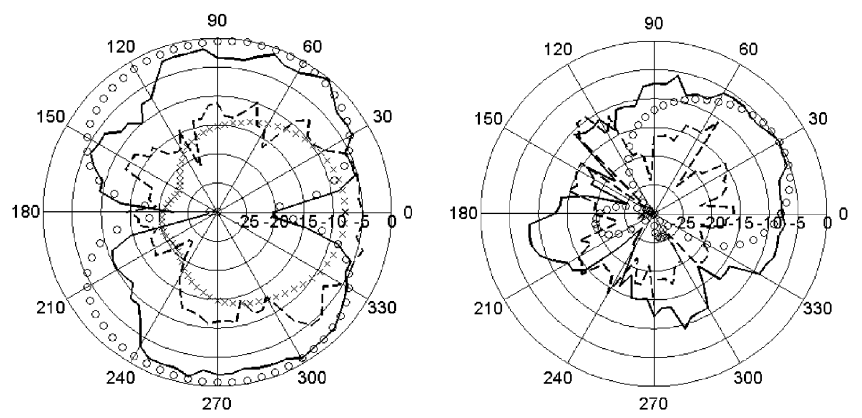

(b) $5200 \mathrm{MHz}$

Fig. 5. Simulated and measured normalized radiation patterns of the proposed antenna for two planes (left: $\mathbf{x}-\mathbf{z}$ plane, right: $\mathbf{y}-\mathbf{z}$ plane) at (a) $2450 \mathrm{MHz}$ and (b) $5200 \mathrm{MHz}$. "xxxx" simulated cross-polarization, "oooo" simulated co-polarization, "------" measured cross-polarization, "____ measured co-polarization.

it away from its desired operating frequencies. According to [13], this is because the ground plane resonates at the operating frequency of the antenna element, so the bandwidth of the antenna-chassis combination will improve considerably. On the contrary, if the ground plane resonates far away from the operating frequency, the bandwidth will be decreased due to the insignificant contribution of the ground plane.

Next, a coaxial cable was connected to the antenna and the change of the return loss investigated when the length of the cable (d) was varied from 0 to $120 \mathrm{~mm}$. As seen in Fig. 2(d), all the return loss curves for various coaxial lengths are approximately identical, and this confirms the configuration of the selected ground and unbalanced feed to this particular antenna design.

\section{RESUlTS AND DisCUSSION}

A physical realization of the proposed antenna was tested with an HP8720B network analyzer, and the computed return loss was predicted by using two commercial packages (CST [11] and IE3D [12]). Fig. 3 illustrates the computed and measured return loss of the proposed antenna: here it can be clearly seen that two resonant modes of the proposed antenna are observed at $2.5 \mathrm{GHz}$ and $5.3 \mathrm{GHz}$. The lower mode provides $8 \%$ relative bandwidth from $2400-2600 \mathrm{MHz}$ at a minimum return loss of $-10 \mathrm{~dB}$ or less, completely encompassing the desired IEEE802.11b/g, Bluetooth and ZigBee frequency band (2400-2485 $\mathrm{MHz}$ ). The upper mode around $5.3 \mathrm{GHz}$ fully covers the IEEE 802.11a $(5.15-5.35 \mathrm{GHz})$ band. As can be observed, simulated and measured results were found to be in excellent agreement.

Fig. 4(a) and (b) shows the simulated and measured gain of the designed antenna in the broadside direction over the frequency ranges from 2400-2480 MHz and 5000-5600 MHz, respectively. At the lower band, a stable measured gain can be observed from 2.6-2.8 dBi. For the upper band, the range of the measured gain varies from about 5.0-5.8
$\mathrm{dBi}$. The overall gain variations are less than $0.8 \mathrm{dBi}$. Both simulated and measured gains are indistinguishable.

Fig. 5(a) and (b) describes the simulated and measured normalized radiation patterns of both co-polarization and cross-polarization in the $\mathrm{x}-\mathrm{z}$ and $\mathrm{y}-\mathrm{z}$ planes at $2450 \mathrm{MHz}$ and $5200 \mathrm{MHz}$ for the proposed antenna. The simulated and measured radiation patterns are seen to be in good agreement.

\section{CONCLUSION}

A dual-frequency planar inverted F-L antenna has been proposed and studied experimentally and theoretically. By balancing the size and bandwidth constraints, the proposed antenna has a compact envelope dimension of $30 \mathrm{~mm} \times 30 \mathrm{~mm} \times 8 \mathrm{~mm}$ and covers the required operating frequency band for the IEEE $802.11 \mathrm{a} / \mathrm{b} / \mathrm{g}$, Bluetooth and ZigBee standards. These features make the proposed antenna an attractive candidate for application in a range of mobile terminals.

\section{ACKNOWLEDGMENT}

The authors express their deep appreciation to their colleague Dr. N. J. McEwan for his support in the antenna simulations and his insightful comments on the revised version of this work.

\section{REFERENCES}

[1] K. Fujimoto, A. Henderson, K. Hirasawa, and J. R. James, Small Antennas. Chichester, U.K.: Research Studies Press, 1987, pp. 116-135.

[2] Z. Li and Y. Rahmat-Samii, "Optimization of PIFA-IFA combination in handset antenna designs," IEEE Trans. Antennas Propag., vol. 53, pp. 1770-1778, May 2005.

[3] M. Z. Azad and M. Ali, "A new class of miniature embedded inverted-F antennas (IFAs) for $2.4 \mathrm{GHz}$ WLAN application," IEEE Trans. Antennas Propag., vol. 54, pp. 2585-2592, Sep. 2006.

[4] Y.-S. Wang, M.-C. Lee, and S.-J. Chung, "Two PIFA-related miniaturized dual-band antennas," IEEE Trans. Antennas Propag., vol. 55, pp. 805-811, Mar. 2007.

[5] J. Janapsatya, K. P. Esselle, and T. S. Bird, "A dual-band and wideband planar inverted-F antenna for WLAN applications," Microw. Opt. Technol. Lett., vol. 50, pp. 138-141, Jan. 2008.

[6] R. A Bhatti and S. O. Park, "Hepta-band internal antenna for personal communication handsets," IEEE Trans. Antennas Propag., vol. 55, no. 12, pp. 3398-3403, Dec. 2007.

[7] M.-C. Huynh and W. Stutzman, "Ground plane effects on planar inverted-F antenna (PIFA) performance," Proc. Inst. Elect. Eng. Microw., Antennas Propag., vol. 150, pp. 209-213, Aug. 2003.

[8] R. Feick, H. Carrasco, M. Olmos, and H. D. Hristov, "PIFA input bandwidth enhancement by changing feed plate silhouette," Electron. Lett., vol. 40, pp. 921-922, Jul. 2004.

[9] H. Nakano, N. Ikeda, Y.-Y. Wu, R. Suzuki, H. Mimaka, and J. Yamauchi, "Realization of dual-frequency and wide-band VSWR performances using normal-mode helical and inverted-F antenna," IEEE Trans. Antennas Propag., vol. 46, pp. 788-793, Jun. 1998.

[10] S. Maci and G. B. Gentili, "Dual frequency patch antennas," IEEE Antennas Propag. Mag., vol. 39, pp. 13-20, Dec. 1997.

[11] CST Microwave Studio5.0 ed. Darmstadt, Germany, Computer Simulation Technology Corp.

[12] IE3D12 ed. USA, Zeland Software, Inc., 2007.

[13] P. Vainikainen, J. Ollikainen, O. Kivekas, and I. Kelander, "Resonator-based analysis of the combination of mobile handset antenna and chassis," IEEE Trans. Antennas Propag., vol. 50, pp. 1433-1444, Oct. 2002. 